\title{
tPA Helpers in the Treatment of Acute Ischemic Stroke: Are They Ready for Clinical Use?
}

\author{
Jong S. Kim \\ Department of Neurology, Asan Medical Center, University of Ulsan College of Medicine, Seoul, Korea
}

Tissue plasminogen activator (tPA) is the only therapeutic agent approved to treat patients with acute ischemic stroke. The clinical benefits of tPA manifest when the agent is administered within 4.5 hours of stroke onset. However, tPA administration, especially delayed administration, is associated with increased intracranial hemorrhage (ICH), hemorrhagic transformation ( $\mathrm{HT})$, and mortality. In the ischemic brain, vascular remodeling factors are upregulated and microvascular structures are destabilized. These factors disrupt the blood brain barrier (BBB). Delayed recanalization of the vessels in the presence of relatively matured infarction appears to damage the $\mathrm{BBB}$, resulting in $\mathrm{HT}$ or $\mathrm{ICH}$, also known as reperfusion injury. Moreover, $\mathrm{PPA}$ itself activates matrix metalloproteases, further aggravating BBB disruption. Therefore, attenuation of edema, $\mathrm{HT}$, or $\mathrm{ICH}$

Correspondence: Jong S. Kim Department of Neurology, Asan Medical Center, University of Ulsan College of

Medicine, 88 Olympic-ro 43-gil, Songpa-gu, Seoul 05505, Korea

Tel: +82-2-3010-3442

Fax: +82-2-474-4691

E-mail: jongskim@amc.seoul.kr

Received: March 11, 2019

Revised: April 4, 2019

Accepted: April 15, 2019 after tPA treatment is an important therapeutic strategy that may enable clinicians to extend therapeutic time and increase the probability of excellent outcomes. Recently, numerous agents with various mechanisms have been developed to interfere with various steps of ischemia/ reperfusion injuries or BBB destabilization. These agents successfully reduce infarct volume and decrease the incidence of $\mathrm{ICH}$ and $\mathrm{HT}$ after delayed $\mathrm{PAA}$ treatment in various animal stroke models. However, only some have entered into clinical trials; the results have been intriguing yet unsatisfactory. In this narrative review, I describe such drugs and discuss the problems and future directions. These "tPA helpers" may be clinically used in the future to increase the efficacy of tPA in patients with acute ischemic stroke.

Keywords Tissue plasminogen activator; Stroke; Thrombolysis; Adjuvant therapy; Neuroprotection

\section{Introduction}

Currently, tissue plasminogen activator (tPA) is the only therapeutic agent approved to treat patients with acute ischemic stroke (AIS). ${ }^{1}$ The clinical benefits of tPA treatment manifest when it is administered within 4.5 hours of stroke onset. ${ }^{2-4}$ However, intravenous (IV) tPA administration is associated with increased occurrence of intracranial hemorrhage $(\mathrm{ICH})$ and hemorrhagic transformation (HT)., ${ }^{3,5}$ Particularly, delayed tPA administration increases the risk of edema, $\mathrm{HT}$, and ICH in both experimental animal models ${ }^{6}$ and patients with AIS. ${ }^{6}$
In the ischemic brain, vascular remodeling factors are upregulated and microvascular structures are destabilized, causing blood brain barrier (BBB) disruption. The breakdown of the BBB combined with delayed vessel reperfusion renders the ischemic brain tissue vulnerable to edema, $\mathrm{HT}$, and $\mathrm{ICH}_{1}{ }^{7-10}$ a phenomenon often called reperfusion injury. In one clinical study, early BBB disruption, detected by gadolinium enhancement in magnetic resonance imaging (MRI), predicted a higher risk of symptomatic HT. ${ }^{11}$ Moreover, tPA itself is neurotoxic and aggravates the brain damage caused by glutamic acid release after ischemia if it leaks into the brain parenchyma. tPA promotes 
leukocyte infiltration, microglial activation, and free radical production in the ischemic brain. ${ }^{12}$ More importantly, it activates matrix metalloproteases (MMPs) that further aggravate BBB disruption., ${ }^{9,13,14}$ Therefore, apart from recanalization, attenuation of the development of edema, $\mathrm{HT}$, and ICH after tPA treatment is an important therapeutic consideration.

Although many neuroprotective agents interfere with the ischemic cascade ${ }_{1}^{15}$ previous trials have failed to confirm their clinical efficacy in stroke patients, even when administered early. ${ }^{16,17}$ This therapeutic failure may occur because drug delivery to the ischemic brain area is poor in cases of decreased blood flow and occluded cerebral blood vessels..$^{18,19}$ Neuroprotectants may work better when reperfusion therapy is concomitantly achieved. ${ }^{3}$ Particularly, if the neuroprotectants can also stabilize the $B B B$, they may be used as "tPA helpers" to protect dying neurons and decrease the incidence of $\mathrm{ICH}$ or $\mathrm{HT}_{1}^{20-22}$ eventually resulting in more favorable functional outcomes in patients undergoing TPA therapy. They may enable clinicians extend the time window for IPA therapy. Agents inhibiting vascular thrombosis may also serve as TPA helpers. ${ }^{23,24}$ Drugs with various mechanisms have been developed for this purpose, and numerous preclinical studies have examined their efficacy. Unfortunately, few well-designed clinical trials have been published. In this narrative review, I describe the various potential tPA helpers that have been developed to increase the efficacy and decrease the side effects of tPA in patients with AIS.

\section{Agents that have shown benefits in preclinical studies}

Various drugs have been developed as tPA helpers, and mostly through mechanisms such as anti-inflammation, suppression of MMP activation, vascular protection, or a combination of these. Although the mechanisms are often multiple, I will describe them according to their main mechanisms (Table 1).

\section{Anti-inflammation and suppression of MMP activation}

\section{Tumor necrosis factor-a inhibitor}

In one study, investigators intracisternally administered either tumor necrosis factor TNF- $a$ or a goat-anti-rabbit-TNF- $a$ antibody to rabbits subjected to stroke. ${ }^{25}$ TNF- $\alpha$ administration increased the incidence of stroke-induced hemorrhage from $18.5 \%$ to $53.3 \%$ ( $188 \%$ increase). Meanwhile, tPA administration $(3.3 \mathrm{mg} / \mathrm{kg})$ increased hemorrhage incidence from $18.5 \%$ to $76.5 \%$ (314\% increase). This effect was reversed by an antiTNF- $a$ antibody; in the tPA+anti-TNF- $a$ antibody group, the hemorrhage rate was $38.8 \%$.

\section{GM6001}

GM6001 binds to the active sites of MMPs and prevents conversion of pro-MMPs into active forms. It attenuates the degradation of tight junction proteins, such as zona occludens (Z0)-1 and occludin in rats, so it may ameliorate BBB damage. ${ }^{26}$ In one study, ${ }^{27}$ mice subjected middle cerebral artery (MCA) occlusion (MCA0) were treated with vehicle, delayed tPA (10 mg/kg; IV) alone, or tPA+GM6001 (100 mg/kg; intraperitoneal). GM6001 significantly reduced MMP-9 activation and inhibited the TPA-induced degradation of occludin and ZO1. Treatment with GM6001 also significantly improved the survival rate and locomotor activity after 7 days.

\section{Niaspan}

Niaspan, an extended-release formulation of niacin, is widely used to increase the level of high-density lipoprotein cholesterol and prevent cardiovascular diseases. In one study, rats were subjected to embolic MCAO and treated with lowdose Niaspan alone ( $n=7$; oral Niaspan; $20 \mathrm{mg} / \mathrm{kg} 4$ hours after MCAO and then daily for 7 days), tPA alone (10 $\mathrm{mg} / \mathrm{kg} ; \mathrm{n}=7)$, a combination $(n=7)$, or saline control $(n=9), 4$ hours after stroke. $^{28}$ Low-dose Niaspan+tPA significantly improved functional outcomes and reduced infarct volume compared to the saline control group, while treatment with Niaspan or tPA alone did not. Combination treatment reduced apoptosis and decreased the expression of TNF- $a$ and Toll-like receptors in the ischemic brain compared to the monotherapy groups. These results suggest that Niaspan's effect is mediated through the modulation of neuroinflammation.

\section{Pyrrolidine dithiocarbamate}

Pyrrolidine dithiocarbamate (PDTC) is a small molecule with anti-inflammatory and anti-oxidant properties. It inhibits nuclear factor (NF)-KB activation and activates Akt protein, which is believed to be pro-survival. ${ }^{29}$ In one study, rats were subjected to embolic right MCAO and administered IV tPA (10 mg/kg) 4 hours later. PDTC ( $50 \mathrm{mg} / \mathrm{kg}$ ) was administered via gastric gavage either 30 minutes or 4 hours after stroke onset. Two days after the stroke, the neurological outcomes were evaluated, and the right frontal cortex area, an ischemic penumbral region, was harvested for analysis. PDTC administered $30 \mathrm{~min}-$ utes but not 4 hours after the stroke reduced infarct volume and improved neurological functions. It also reduced the prevalence of tPA-induced hemorrhages and attenuated the expression of proinflammatory cytokines, oxidative stress, and MMP-2 activity in the right frontal area. ${ }^{30}$ Given early, PDTC 
Table 1. Drugs that showed benefits in animal models of stroke treated by tPA

\begin{tabular}{|c|c|c|c|}
\hline Agent & Presumed mechanisms & Animal model & Comments \\
\hline Anti-TNF- $a$ antibody & Antiinflammation, MMP inactivation & Rabbit, embolic & \\
\hline GM6001 & MMP inactivation & Mice, transient MCAO & Inhibited tPA induced degradation of occludin \\
\hline Niacin & Antiinflammation & Rat, embolic MCAO & $\begin{array}{l}\text { Reduced expression of TNF-a and Toll-like recep- } \\
\text { tors }\end{array}$ \\
\hline Pyrrolidine dithiocarbamate & Antiinflammation, Anti-oxidant & Rat, embolic MCAO & Inhibits nuclear factor (NF)-кB activation \\
\hline $\begin{array}{l}\text { Granulocyte colony-stimulat- } \\
\text { ing factor }\end{array}$ & Improving angiogenesis & Rat, transient MCAO & $\begin{array}{l}\text { Increased angiogenesis markers and VEGF expres- } \\
\text { sion }\end{array}$ \\
\hline Bryostatin & Protein kinase $\mathrm{C}$ activator, MMP inactivation & Rat, embolic MCAO & \\
\hline BAY 60-6583 & $\begin{array}{l}\text { Adenosine } \mathrm{A} 2 \mathrm{~b} \text { receptor agonist, MMP inactiva- } \\
\text { tion }\end{array}$ & Rat, transient MCAO & \\
\hline Progesterone & MMP inactivation & Rat, MCAO & \\
\hline Baicalin & MMP inactivation & Rat, transient MCAO & \\
\hline Neuroserpin & Blocking extravascular tPA effects & Rat, embolic MCAO & $\begin{array}{l}\text { Reduced the blood brain barrier disruption detected } \\
\text { by MRI }\end{array}$ \\
\hline $\begin{array}{l}\text { Transforming growth } \\
\text { factor- } \beta 1\end{array}$ & $\begin{array}{l}\text { Blocking extravascular tPA effects, MMP inacti- } \\
\text { vation }\end{array}$ & Rat, MCAO & \\
\hline Minocycline & Antiinflammation, MMP inactivation & Rat, embolic MCAO & \\
\hline Uric acid & Anti-oxidant, Endothelial protection & Rat, embolic MCAO & \\
\hline Statin & $\begin{array}{l}\text { Antiinflammation, MMP inactivation, Anti-oxi- } \\
\text { dant }\end{array}$ & Rabbit, embolic & \\
\hline Edaravone & Antioxidant, Antiinflammation & Rat, transient MCAO & \\
\hline GP IIb/IIla receptor antagonist & Antiplatelet & Rat, embolic MCAO & Decreased microvascular platelet accumulation \\
\hline 3К $3 \mathrm{~A}-\mathrm{APC}$ & Antiinflammation, antiapoptotic, antithrombotic & Mice, transient MCAO & \\
\hline Fingolimod & Antiinflammation & Mice, transient MCAO & \\
\hline Otaplimastat & Anti-inflammatory, MMP inactivation & Rat, embolic MCAO & \\
\hline Epigallocatechin gallate & Antioxidant, MMP inactivation & Rat, transient MCAO & \\
\hline
\end{tabular}

tPA, tissue plasminogen activator; TNF, tumor necrosis factor; MMP, metalloproteases; MCAO, middle cerebral artery occlusion; VEGF, vascular endothelial growth factor; $\mathrm{MRI}$, magnetic resonance imaging.

may have a neuroprotective effect in subjects using tPA.

\section{Bryostatin (protein kinase Cactivator)}

In one study, rats received either TPA (6 hours after MCA0) or tPA+bryostatin, a potent protein kinase C (PKC) activator (6 hours, followed by $3,6,9,12,15$, and 18 days after MCA0). Bryostatin-treated rats showed improved survival, as well as reduced infarct volume, hemispheric swelling, and improved neurological function 21 days after MCAO. ${ }^{31}$ In another study, ${ }_{1}^{32}$ bryostatin (or vehicle) was administered 2 hours after MCAO, while IV tPA was administered 6 hours after MCAO. Rats treated with bryostatin prior to TPA administration showed decreased hemispheric swelling compared to rats treated with tPA alone. Administration of bryostatin also attenuated BBB disruption and $\mathrm{HT}$, and down-regulated MMP-9 expression while up-regulating PKC expression 24 hours after MCAO.

\section{BAY 60-6583 (adenosine A2b receptor agonist)}

The adenosine $\mathrm{A} 2 \mathrm{~b}$ receptor (A2bR) regulates vascular protection. In one study, ${ }_{1}^{33}$ investigators used a rat transient MCAO model to show that mRNA and protein expression of $A 2 b R$ increased more after ischemia-reperfusion than did expression of the other three adenosine receptors. tPA administration reduced A2bR expression in ischemic brain microvessels. Posttreatment using BAY $60-6583(1 \mathrm{mg} / \mathrm{kg})$ at the start of reperfusion reduced lesion volume, brain swelling, BBB disruption, and tPA-exacerbated HT after 24 hours. BAY 60-6583 also inhibited tPA-enhanced MMP-9 activation, probably by elevating the expression of tissue inhibitor of MMP-1 and thereby reducing the degradation of tight junction proteins.

\section{Progesterone}

Progesterone has a neuroprotective effect in ischemia. In one 
study, rats undergoing MCAO received either IPA treatment at 4.5 hours, or additional intraperitoneal progesterone treatment at 2 hours followed by subcutaneous progesterone injection 6 hours after MCAO. TPA treatment induced significant HT and brain swelling whereas progesterone+tPA ameliorated $\mathrm{HT}$, edema, BBB permeability, and MMP-9 activation; it also prevented tPA-induced decreases in transendothelial electrical resistance and expression of occludin and claudin- $5{ }^{34}$

\section{Baicalin}

Baicalin $\left(\mathrm{C}_{21} \mathrm{H}_{18} \mathrm{O}_{11} ; 5,6,7\right.$-trihydroxyflavone $7-0-\beta$-d-glucuronide or baicalein 7-0- $\beta$-d-glucuronic acid or 7-d-glucuronic acid-5,6-dihydroxyflavone) is an important flavonoid component in the roots of Scutellaria baicalensis Georgi, which have been used as an oriental herbal medicine. Baicalin has neuroprotective properties mediated through various mechanisms, including anti-oxidative stress, anti-excitotoxicity, anti-apoptosis, anti-inflammation, neurogenesis stimulation, and upregulation of neuronal protective factors. ${ }^{35}$ In a recent study ${ }_{1}^{36}$ rats were subjected to MCAO for 4.5 hours and then received IV tPA $(10 \mathrm{mg} / \mathrm{kg})$ for 0.5 hours, followed by a 19-hour reperfusion. Baicalin $(50,100$, or $150 \mathrm{mg} / \mathrm{kg}$ ) was administrated via the femoral vein 4.5 hours after MCAO. Delayed tPA infusion increased HT, BBB damage, and apoptotic cell death in the ischemic brains, while co-treatment with baicalin significantly reduced $\mathrm{HT}$, tPA-mediated BBB disruption, and MMP-9 activity.

\section{Endothelial protection and improvements in angiogenesis}

\section{Granulocyte colony-stimulating factor}

Rats undergoing MCAO were treated with vehicle, IPA (10 $\mathrm{mg} / \mathrm{kg}$ ), or tPA + IV granulocyte colony-stimulating factor (GCSF) $300 \mu \mathrm{g} / \mathrm{kg} 6$ hours after MCA0. ${ }^{37}$ Twenty-four hours later, the rats given G-CSF+tPA displayed a $25 \%$ improvement in neurological functions and a $38.9 \%$ reduction in hemorrhage. Western blots showed that the rats given G-CSF+tPA had elevated levels of the angiogenesis markers angiopoietin-2 and von-Willebrand factor in the ischemic brain compared with rats treated using tPA only, as well as up-regulation of vascular endothelial growth factor. These findings suggest that G-CSF attenuated the delayed-onset, tPA-induced $\mathrm{HT}$, probably by enhancing angiogenesis. In a subsequent study, G-CSF administration also increased the endothelial progenitor cell population and vasculogenesis in the ischemic brain. ${ }^{38}$

\section{Blocking extravascular tPA effects}

\section{Neuroserpin}

Neuroserpin is a natural inhibitor of tPA and may reduce tPAinduced neurotoxicity. In one study, rats were subjected to embolic MCAO and treated using neuroserpin ( $16 \mu \mathrm{mol} / \mathrm{L}$, at 3 hours)+tPA (10 mg/kg, at 4 hours; $n=7)$, tPA alone $(n=7)$, or saline $(n=9) .{ }^{39} \mathrm{MRI}$ measurements were performed to assess BBB leakage. Neuroserpin+tPA significantly reduced BBB damage, brain edema, and ischemic lesion volume compared with TPA alone. Neuroserpin administration may block the extravascular effect of tPA.

\section{Transforming growth factor- $\beta 1$}

Transforming growth factor- $\beta 1$ (TGF- $\beta 1$ ) promotes extracellular matrix accumulation. In one study, ${ }^{40}$ rats were given saline, tPA (10 mg/kg) alone, or tPA+TGF- $\beta 1$ (2.5 $\mu \mathrm{g}$ per animal; IV over 5 minutes) 3 hours after MCAO. Examination of the brain 24 hours after MCAO showed basement membrane damage, $B B B$ disruption, and $H T$ in rats treated with $\mathrm{TPA}$. These effects were attenuated in rats co-treated with TGF- $\beta$ 1. Furthermore, TGF- $\beta 1$ inhibited TPA-mediated activation of MMP-2 and MMP-9 and up-regulated plasminogen activator inhibitor-1 (PAI-1) expression in brain tissue. TGF- $\beta 1$ may up-regulate $\mathrm{PAI}-1$ expression in the ischemic brain, thereby reducing extravascular tPA activity by forming the PAI-1/tPA complex, resulting in stabilization of tPA-induced BBB disruption.

\section{Drugs that have shown potential benefits in clinical studies}

Drugs that have been examined in clinical studies are presented below and in Table 2. As they usually have diverse action mechanisms, they are not listed according their mechanisms.

\section{Minocycline}

Aside from anti-bacterial effects, minocycline has neuroprotective effects in various neurological disease processes. ${ }^{41}$ In a study using spontaneously hypertensive rats subjected to embolic MCAO, 1-hour TPA therapy restored perfusion and reduced infarction, whereas 6-hour tPA administration worsened HT. Minocycline+6-hour tPA therapy decreased plasma MMP-9 levels, reduced infarct volume, and decreased $\mathrm{ICH}^{42}$ In another study involving rats with type 1 diabetes, ${ }^{43}$ minocycline+tPA significantly reduced brain infarction, edema, and ICH 24 hours after stroke compared with saline or tPA monotherapy. The combination therapy also attenuated neutrophil infiltration, microglial activation, MMP-9 activation, and degradation of 
Table 2. Drugs that showed benefits in clinical studies in patients treated by tPA

\begin{tabular}{|c|c|c|c|c|c|c|}
\hline Agent & Trial name & Trial characteristics & No of patients & $\begin{array}{l}\text { Enrollment from } \\
\text { symptom onset (hr) }\end{array}$ & Administration & Result \\
\hline \multicolumn{7}{|l|}{ Minocycline } \\
\hline $\begin{array}{l}\text { Lampl et al. } \\
(2007)^{45}\end{array}$ & & $\begin{array}{l}\text { R, open-label, } \\
\text { evaluator-blinded }\end{array}$ & 152 & $6-24$ & $\begin{array}{l}200 \text { mg, once daily, oral, } \\
5 \text { days }\end{array}$ & Safe, better in NIHSS, mRS and $\mathrm{BI}$ \\
\hline $\begin{array}{l}\text { Padma Srivastava } \\
\text { et al. }(2012)^{46}\end{array}$ & & $\begin{array}{l}\mathrm{R} \text {, single-blinded } \\
\text { open-label study }\end{array}$ & 50 & $6-24$ & $\begin{array}{l}200 \text { mg, once daily, oral, } \\
5 \text { days }\end{array}$ & Safe, better in NIHSS, mRS and BI \\
\hline Uric acid & $\begin{array}{l}\text { URICO-IC- } \\
\text { TUS }\end{array}$ & $R, D, P$ & 411 & $<4.5$ & $\begin{array}{l}1,000 \mathrm{mg} \text { during tPA } \\
\text { infusion }\end{array}$ & Safe, not proven to be effective \\
\hline Simvastatin & STARS07 & $R, D, P$ & $\begin{array}{l}104 \text { (half re- } \\
\text { ceived tPA) }\end{array}$ & $<12$ & $\begin{array}{l}40 \text { mg once daily, oral, } \\
90 \text { days }\end{array}$ & Safe, not proven to be effective \\
\hline Edaravone & YAMATO & $\begin{array}{l}\mathrm{R} \text { (for timing, no } \\
\text { placebo), open label }\end{array}$ & 165 & $<4.5$ & $\begin{array}{l}\text { Oral, } 30 \text { mg twice/day, } \\
7 \text { days }\end{array}$ & $\begin{array}{l}\text { Safe, timing of edaravone didn't } \\
\text { affect recanalization rate }\end{array}$ \\
\hline \multicolumn{7}{|c|}{ GP IIb/IIla receptor antagonist } \\
\hline Seitz et al. (2004) ${ }^{23}$ & & $R$, open-label & 47 & $<4.5$ & $\begin{array}{l}0.4 \mu \mathrm{g} / \mathrm{kg} / \mathrm{min} \text { for } 30 \mathrm{~min}- \\
\text { utes followed by } 0.1 \\
\mu \mathrm{g} / \mathrm{kg} / \mathrm{min} \text { for } 24 \text { hours }\end{array}$ & Safe, decreased infarct volume \\
\hline Li et al. $(2016)^{68}$ & & $\mathrm{R}$, open-label & 41 & $<4.5$ & $\begin{array}{l}0.4 \mu \mathrm{g} / \mathrm{kg} / \mathrm{min} \text { for } 30 \mathrm{~min}- \\
\text { utes followed by } 0.1 \\
\mu \mathrm{g} / \mathrm{kg} / \mathrm{min} \text { for } 24 \text { hours }\end{array}$ & $\begin{array}{l}\text { Safe, less re-occlusion at } 24 \text { hours, } \\
\text { improved NIHSS score } \\
\text { More favorable mRS at } 3 \text { months }\end{array}$ \\
\hline Argatroban & ARTSS-2 & $\mathrm{R}$ & 90 (2 dosages) & $<4.5$ & $\begin{array}{l}100 \mathrm{U} / \mathrm{kg} \text { bolus+IV } \\
\text { infusion for } 48 \text { hours }\end{array}$ & $\begin{array}{l}\text { Safe, tendency for improved } \\
\text { outcome }\end{array}$ \\
\hline 3К 3 A-APC & RHAPSODY & $R, D, P$ & 110 (4 dosages) & $\begin{array}{l}\text { Patients undergo- } \\
\text { ing tPA or EVT }\end{array}$ & IV infusion twice daily×5 & $\begin{array}{l}\text { Safe, decreased ICH rates and } \\
\text { volume }\end{array}$ \\
\hline Fingolimod & & $\begin{array}{l}\text { R, open label, } \\
\text { evaluator blinded }\end{array}$ & 47 & $4.5-72$ & $0.5 \mathrm{mg}$ every 12 hours $\times 5$ & Safe, more favorable mRS \\
\hline Otaplimastat & SAFE-TPA & $R, D, P$ & 69 (2 dosages) & $<4.5$ & IV infusion twice daily×6 & $\begin{array}{l}\text { Safe, mRS distribution more } \\
\text { favorable with low dosage }\end{array}$ \\
\hline $\begin{array}{l}\text { Epigallocatechin } \\
\text { gallate }\end{array}$ & & $R, D, P$ & 371 & $<4.5$ & $500 \mathrm{mg}$ daily $\times 7$ days & Safe, improved NIHSS score \\
\hline
\end{tabular}

tPA, tissue plasminogen activator; R, randomized; NIHSS, National Institutes of Health Stroke Scale; mRS, modified Rankin Scale; BI, Barthel index; URICO-ICTUS, Efficacy Study of Combined Treatment With Uric Acid and r-tPA in Acute Ischemic Stroke; D, double-blinded; P, placebo-controlled; STARS07, Stroke Treatment with Acute Reperfusion and Simvastatin 07; YAMATO, Tissue-Type Plasminogen Activator and Edaravone Combination Therapy; ARTSS-2, Argatroban with Recombinant Tissue Plasminogen Activator for Acute Stroke; IV, intravenous; RHAPSODY, The Safety Evaluation of 3K3A-activated protein C in Ischemic Stroke; EVT, endovascular thrombectomy; ICH, intracranial hemorrhage; SAFE-TPA, Safety and Efficacy of Otaplimastat in Patients with AIS Receiving recombinant tPA.

the tight junction protein claudin-5 in periinfarct brain tissues.

Minocycline is safe when administered to patients with AIS receiving tPA. ${ }^{44}$ Two small randomized trials used the National Institutes of Health Stroke Scale (NIHSS), modified Rankin Scale (mRS), and Barthel index to show a beneficial effect of minocycline in patients with AIS receiving tPA after 7 days, 30 days, ${ }^{45}$ and 3 months of follow-up. ${ }^{46}$ In 2018 , two systematic reviews were published. ${ }^{44,47}$ In patients with AIS, minocycline was associated with higher proportions of patients with 3-month mRS-scores of 0-2 (risk ratio, 1.59; 95\% confidence interval $[\mathrm{Cl}], 1.19$ to $\left.2.12 ; P=0.002 ; I^{2}=58 \%\right)$, whereas reduced 3-month NIHSS scores (mean difference, 2.84; $95 \% \mathrm{Cl}, 5.55$ to $0.13 ; P=0.04 ; I^{2}=86 \%$ ). Although data remain limited, minocycline is a promising neuroprotective agent in patients with AIS. The West Australian Intravenous Minocycline and tPA Stroke
Study (WAIMATSS) ${ }^{48}$ aimed to determine the safety and efficacy of adding minocycline to TPA in patients with AIS. Although patients in the minocycline group had lower plasma MMP-9 levels, the main results are not yet available. ${ }^{49}$

\section{Uric acid}

Uric acid is an endogenous antioxidant derived from purine metabolism. It also prevents the production of superoxide, nitric oxide, nitric oxide synthase (NOS), endothelial NOS, interleukin 18 in the ischemic arterial wall, and nitrosylated protein in the brain, suggesting that uric acid-mediated neuroprotection mainly drives from the protected cerebral vasculature..$^{50}$ In an experiment using thromboembolic MCAO rat models, ${ }_{1}^{51} \mathrm{IV}$ uric acid $(16 \mathrm{mg} / \mathrm{kg})$ was injected 20 minutes after MCAO, whereas IV tPA (10 mg/kg) was administered after 3 hours. A third group 
of rats received a combined treatment. Treatment using either uric acid or tPA reduced infarct volume compared with controls, but the protective effect was greater with uric acid+tPA.

Efficacy Study of Combined Treatment With Uric Acid and rtPA in Acute Ischemic Stroke (URICO-ICTUS) trial ${ }^{52}$ was a randomized, double-blind, placebo-controlled, phase $2 b / 3$ trial that recruited patients with AIS undergoing TPA treatment, who additionally received either IV uric acid $(1,000 \mathrm{mg})$ or a placebo. The primary outcome was the proportion of patients with an mRS score of 0-1 after 90 days. Four hundred and eleven patients (211 receiving uric acid, 200 receiving a placebo) were enrolled. Thirty-nine percent of the patients who received uric acid and 33\% in the placebo group had an excellent outcome (adjusted risk ratio, $1.23 ; 95 \% \mathrm{Cl}, 0.96$ to 1.56 ; $P=0.099$ ). No significant differences were reported between groups with respect to death (13\% vs. $16 \%$ ), symptomatic ICH ( $4 \%$ vs. $3 \%$ ), and serious adverse events (SAEs; $12 \%$ vs. $13 \%$ ). The addition of uric acid to tPA therapy was safe, but did not improve clinical outcomes.

Secondary analysis showed that the primary outcome had been achieved in several subgroups, including those who had received endovascular thrombectomy (EVT) as part of their reperfusion therapy..$^{53}$ In addition, uric acid administration decreased the incidence of early neurological worsening. ${ }^{52}$ The Uric acid in Reperfusion Injury Control (URIC) trial was recently planned to validate the URICO-ICTUS results in a larger population of patients treated using EVT. ${ }^{50}$

\section{Statins}

Although statins are widely-used lipid lowering agents, they have many other benefits; they have antioxidant properties, inhibit inflammation and MMP-9 activation, and increase nitric oxide bioavailability, thereby improving endothelial function. ${ }^{54}$

One study ${ }^{55}$ showed that IV tPA (3.3 $\mathrm{mg} / \mathrm{kg}$, IV) 1 hour following clot-embolization significantly increased hemorrhage volume (by 175\%) and hemorrhage incidence (by 60\%) compared to control in white rabbits. Simvastatin $(20 \mathrm{mg} / \mathrm{kg})$ administered subcutaneously 24 and 4 hours prior to clot embolization significantly decreased the incidence of tPA-induced hemorrhage $(P=0.022)$ and infarct volume $(P=0.0001)$. Another study ${ }^{56}$ investigated the neuroprotective effects of atorvastatin in combination with delayed tPA therapy in rats subject to embolic MCAO. TPA infusion at 6 hours increased the incidence of $\mathrm{HT}$ and failed to reduce infarct volume compared with the control group. However, adjuvant treatment with atorvastatin at 4 hours reduced tPA-induced up-regulation of protease activated receptor 1 (PAR1), intercellular adhesion molecule-1 (ICAM-1), and MMP-9, and reduced cerebral microvascular platelet levels, neutrophil count, and fibrin deposition compared with rats treated using TPA alone. Both studies suggested that statins can attenuate IPA-induced hemorrhage.

Stroke Treatment with Acute Reperfusion and Simvastatin (STARS) $07^{57}$ was a multicenter, randomized, double-blind, placebo-controlled trial aiming to assess the efficacy and safety of simvastatin treatment in acute stroke. Patients with AIS were randomized into the oral simvastatin $(40 \mathrm{mg}$ ) or placebo groups and treated once daily for 90 days. The primary outcome was the proportion of patients with $\mathrm{mRS}$ scores $\leq 2$ after 90 days. One hundred-four patients were enrolled, with about half (55 patients) receiving IV tPA. No differences were found between the treatment arms regarding primary outcome (adjusted odds ratio, $0.99 ; 95 \% \mathrm{Cl}, 0.35$ to $2.78 ; P=0.98$ ) or rate of $\mathrm{HT}$. In post hoc analyses of patients receiving $\mathrm{TPA}$, a favorable effect of simvastatin treatment was noted, with a higher proportion of patients experiencing major neurological recovery (adjusted odds ratio, $4.14 ; 95 \% \mathrm{Cl}, 1.18$ to $14.4 ; P=0.02$ ).

The EUREKA study (effects of very early use of rosuvastatin in preventing recurrence of ischemic stroke), ${ }^{58}$ attempted to examine the effect and safety of rosuvastatin in patients with AIS. This randomized, double-blind, multi-center trial compared rosuvastatin $(20 \mathrm{mg})$ with a placebo in statin-naïve stroke patients who underwent diffusion-weighted imaging (DWI) within 48 hours of symptom onset. The primary outcome was occurrence of new ischemic lesions on follow-up DWI after 5 or 14 days. This trial was stopped early after randomization of 316 patients due to slow enrollment. Among 289 patients with at least one follow-up imaging, the frequency of new ischemic lesions on DWI (rosuvastatin 19.7\% vs. placebo $23.6 \%$ ) as well as infarct volume growth after 5 days, did not differ between the two groups. However, brain hemorrhages detected on gradient-recalled echo MRI occurred less frequently in the rosuvastatin group $(6 / 137 ; 4.4 \%)$ than in the placebo group $(22 / 152$; $14.5 \%$; $P=0.007$ ), suggesting that statin use in AIS may prevent $H T$, possibly associated with statin's effect in inhibiting MMP-9 activation. ${ }^{54}$ Unfortunately, the number of patients who had received tPA was very low in this study (four in the rosuvastatin group, five in the placebo group), so it was impossible to assess the efficacy of rosuvastatin in preventing tPA-associated hemorrhages.

\section{Edaravone}

Edaravone, a free radical scavenger, confers a neuroprotective effect by inhibiting vascular endothelial cell injury and ameliorating neuronal damage in ischemic brain models. In one study involving spontaneously hypertensive rats subjected to MCAO, the animals were administered vehicle alone, tPA alone, or 
edaravone+tPA. Electron microscopic analyses showed that the basement membrane was disintegrated and detached from the astrocyte endfeet in IPA-treated animals, which was associated with $\mathrm{HT}$. Edaravone prevented dissociation of the neurovascular unit, dramatically decreased $\mathrm{HT}$, and improved the neurological score and survival rate of the rats. ${ }^{59}$

Investigators in the Tissue-Type Plasminogen Activator and Edaravone Combination Therapy (YAMATO) study ${ }^{60}$ attempted to assess whether edaravone administration before or during tPA therapy can expedite the recanalization of occluded arteries. This was a multicenter, prospective, randomized, and openlabel study. One-hundred and sixty-five patients with AIS secondary to MCAO were randomly allocated to the early group (IV edaravone [30 mg] started before or during tPA) and the late group (edaravone started after tPA). Recanalization, $\mathrm{ICH}_{\text {, and }}$ favorable outcome (mRS score of 0-2) after 3 months were similar between the groups, suggesting that the timing of edaravone infusion does not affect the clinical outcome. A recent, large observational study provided some evidence that edaravone is associated with better functional outcome when it is used in patients who have undergone acute EVT. ${ }^{61}$ Unfortunately, no qualified studies have yet compared edaravone+tPA with placebo+tPA.

\section{GP Ilb/Illa receptor antagonist}

The overall recanalization rate is approximately $46 \%$ after IV tPA. ${ }^{62}$ However, re-occlusion after initial recanalization occurs in $14 \%$ to $34 \%$ of patients and is associated with early neurological deterioration. Re-occlusion usually occurs due to activated platelet aggregation and endothelial damage. ${ }^{63,64} \mathrm{Al}-$ though early administration of antiplatelet agents after IV tPA may prevent platelet aggregation and subsequent vascular reocclusion, the Antiplatelet Therapy in Combination With Recombinant tPA Thrombolysis in Ischemic Stroke (ARTIS) trial concluded that early IV administration of aspirin (300 mg) shortly after recombinant tPA did not improve outcomes after 3 months, but that it significantly increased the rate of symptomatic $\mathrm{ICH} .{ }^{65}$ However this failure may have been due to the long-lasting and irreversible anti-platelet effects of aspirin.

A GP IIb/Illa receptor antagonist has a short half-life and blocks the final pathway to platelet aggregation and thrombus formation. In one study, rats were subjected to embolic MCAO and treated with a GP Ilb/llla antagonist, 7E3 F(ab')2 (6 mg/kg)+tPA (10 and $5 \mathrm{mg} / \mathrm{kg}$ ), tPA alone, 7E3 F(ab')2 alone, or saline 4 hours after MCA0. The results showed that 7E3 F(ab')2+tPA significantly reduced infarct volume and neurological deficits compared with the saline-treated rats, whereas monotherapy did not. Quantitative measurements of cerebral microvessels revealed that
7E3 F(ab')2+tPA significantly increased the percentage of fluorescein isothiocyanate-dextran-perfused vessels, and that it decreased microvascular platelet accumulation and MMP-9 immunoreactivity compared with rats receiving monotherapy. ${ }^{66}$

One open label clinical tria| ${ }^{23}$ studied 47 patients with AIS to investigate the clinical efficacy of IV tPA+tirofiban. Compared with tPA monotherapy $(0.9 \mathrm{mg} / \mathrm{kg})$, tPA $(20 \mathrm{mg})+$ tirofiban $(0.4 \mu \mathrm{g} / \mathrm{kg} / \mathrm{min}$ for 30 minutes), followed by continuous infusion of $0.1 \mu \mathrm{g} / \mathrm{kg} / \mathrm{min}$ for 24 hours, reduced the MRI-identified infarct volume on day 8 (50\% vs. 30\%, $P<0.03$ ). No symptomatic ICH was observed among the subjects. Another study ${ }^{67}$ reported that MCA recanalization was achieved in 68\% of 19 patients with acute MCAO using the combined treatment strategy, compared to $46 \%$ of patients treated using conventional IV tPA. In a recent prospective, open-label trial, Li et al. ${ }^{68}$ re-investigated this issue in 41 patients with AIS. The incidence of $\mathrm{ICH}_{\text {, mortali- }}$ ty, and clinical outcomes were similar between the combined therapy group (tPA $[0.9 \mathrm{mg} / \mathrm{kg}]+$ tirofiban $[0.4 \mu \mathrm{g} / \mathrm{kg} / \mathrm{min}$ for 30 minutes followed by continuous infusion of $0.1 \mu \mathrm{g} / \mathrm{kg} / \mathrm{min}$ for at least 24 hours]) and the standard tPA therapy group. However, the combined therapy group showed less re-occlusion after 24 hours (2.4\% vs. $22.0 \%, P=0.025)$, lower NIHSS score at day 7 or discharge ( 1 vs. $6, P=0.002$ ), and more favorable functional outcomes after 3 months $(70.7 \%$ vs. $46.2 \%, P=0.026)$. These preliminary trials suggest that combined therapy may be superior to IPA monotherapy.

\section{Argatroban}

Argatroban selectively inhibits free and clot-associated thrombin. In the rabbit arterial thrombosis model, it safely augments the benefits of tPA by improving the rate of recanalization and preventing re-occlusion. ${ }^{69}$ In one study using the rat embolic MCAO model, either TPA or TPA+argatroban was administered 4 hours after MCAO. A significant reduction in lesion volume and fibrin deposition in the ipsilateral cortical microvasculature were observed in the argatroban+tPA group compared with controls. No increase in HT was observed. ${ }^{70}$

The Argatroban Anticoagulation in Patients with Acute Ischemic Stroke (ARGIS-1) study showed that argatroban monotherapy, with mean doses of 1.2 and $2.7 \mu \mathrm{g} / \mathrm{kg} / \mathrm{min}$ given within 12 hours, was safe in patients with AIS. ${ }^{11}$ The Argatroban tPA Stroke Study ${ }^{71}$ was an open-label, pilot study of tPA+argatroban treatment in patients with AIS caused by proximal intracranial occlusion. During standard-dose IV tPA therapy, a $100-\mu \mathrm{g} / \mathrm{kg}$ bolus of argatroban, followed by infusion for 48 hours, was adjusted to correspond with a target partial thromboplastin time of $1.75 \times$ baseline. Significant ICH had occurred in four patients (6.2\%) and recanalization had occurred in 29 patients (61\%) at the 2-hour monitoring period. 
Argatroban with Recombinant Tissue Plasminogen Activator for Acute Stroke (ARTSS-2) was a randomized, multicenter study that assessed the safety and functional outcome of adjunctive argatroban administered to tPA-treated patients who had not undergone EVT. ${ }^{24}$ Patients were randomized to receive either no argatroban or argatroban ( $100 \mu \mathrm{g} / \mathrm{kg}$ bolus) followed by infusion of either $1 \mu \mathrm{g} / \mathrm{kg} / \mathrm{min}$ (low dose) or $3 \mu \mathrm{g} / \mathrm{kg} / \mathrm{min}$ (high dose) for 48 hours. Ninety patients were randomized: 29 to the tPA alone group, 30 to the tPA+low-dose argatroban group, and 31 to the tPA+high-dose argatroban group. After 90 days, $21 \%, 30 \%$, and $32 \%$ of these patients had an $m R S \leq 1$, respectively, while the rates of symptomatic $\mathrm{ICH}$ were similar. The result suggested that argatroban may provide a clinical benefit. Finally, the Safety and Feasibility of Argatroban, Recombinant Tissue Plasminogen Activator, and Intra-Arterial Therapy in Stroke (ARTSS-IA) study aimed to ascertain the feasibility and safety of tPA+argatroban in patients undergoing EVT. $^{72}$ In this single-arm study, all 10 enrolled patients received argatroban before EVT, with no delays in time-metrics compared to non-study patients. Nine patients achieved good reperfusion (Treatment In Cerebral Ischemia grade $\geq 2 b$ ) and none had symptomatic ICH or EVT complications.

\section{K3A-activated protein C}

Protein $C$ is a plasma serine protease zymogen whose active form, activated protein C (APC), exerts a potent anticoagulant activity. In addition, APC has both anti-inflammatory and antiapoptotic properties in cultured endothelial cells. ${ }^{73}$ Preclinical studies have indicated that the G-protein-coupled receptor, PAR1, is necessary for APC's diverse pharmacologic effects, and biased signaling mediated by PAR1 is thought to be central to APC's clinical benefits. ${ }^{74,75}$

In the mouse model of transient $\mathrm{MCAO}_{1}^{76}$ treatment using purified human plasma-derived APC ( $2 \mathrm{mg} / \mathrm{kg})$, delivered IV either 15 minutes before or 10 minutes after stroke induction, reserved cerebral blood flow, reduced infarct volume and brain edema, eliminated brain neutrophil infiltration, reduced the number of fibrin-positive cerebral vessels, and inhibited ICAM1 expression on ischemic cerebral blood vessels. These results suggest that APC's anti-inflammatory, antithrombotic, and neuroprotective effects improve BBB maintenance. Further studies showed that APC infused simultaneously with, or 3 hours after, IV tPA markedly reduced infarct volume and IPAinduced hemorrhage in mouse models of embolic MCAO. APC also inhibited the pro-inflammatory up-regulation of NF-KB by tPA, and the effects were not observed in PAR1 null mice. ${ }^{77}$

Another study engineered APC by site-directed mutagenesis to produce a selective APC mutant that had three lysine resi- dues replaced by three alanine residues (3K3A-APC). This mutant lacks $>90 \%$ of the anticoagulant activity of APC, but retains normal cell signaling. ${ }^{75}$ In a study using a rodent MCAO model, ${ }^{78}$ when tPA was given 4 hours after MCAO, it provided no benefit; rather, it introduced bleeding. In contrast, additional administration of 3K3A-APC reduced infarct volume and eliminated tPA-associated bleeding.

3K3A-APC appears to be safe in human beings. ${ }^{79}$ The Safety Evaluation of $3 \mathrm{~K} 3 \mathrm{~A}$-activated protein $\mathrm{C}$ in Ischemic Stroke (RHAPSODY) was a phase 2, randomized, controlled, blinded trial that aimed to determine the maximum tolerated dose of 3K3A-APC in AIS patients receiving IV tPA, EVT, or both..$^{80}$ One of four doses of 3K3A-APC $(120,240,360$, or $540 \mu \mathrm{g} / \mathrm{kg})$ or placebo was randomly administered in 110 patients. The maximum tolerated dose was $540 \mu \mathrm{g} / \mathrm{kg}$. Although there was no difference in prespecified ICH rates, 3K3A-APC reduced ICH rates compared to placebo from $86.5 \%$ to $67.4 \%(P=0.046)$ and total hemorrhage volume from an average of $2.1 \pm 5.8$ to $0.8 \pm 2.1 \mathrm{~mL}(P=0.066)$.

\section{Fingolimod}

Lymphocytes interact with endothelial cells and platelets (thrombo-inflammation), resulting in microvascular dysfunction and infarct growth in the ischemic brain. Fingolimod, a sphingosine-1-phosphate receptor modulator, blocks the egress of lymphocytes from lymphoid organs and reduces the vascular brain damage. ${ }^{81}$ In the mouse model of transient MCAO, fingolimod significantly reduced infarct size and improved functional outcome in wild-type mice. This protective effect was lost in lymphocyte-deficient Rag ${ }^{1-1}$ mice. Fewer lymphocytes were present in the cerebral vasculature of fingolimod-treated wildtype mice, which showed reduced thrombosis and increased cerebral perfusion. ${ }^{82}$

In an open-label, evaluator-blinded, multicenter trial, ${ }^{83}$ investigators randomly administered tPA+oral fingolimod ( 0.5 $\mathrm{mg}$ ) once daily for 3 days $(n=22)$ or tPA only $(n=25)$ in patients with AIS. Compared with patients receiving IPA alone, those who received the fingolimod+tPA exhibited fewer circulating lymphocytes, smaller lesion volumes $(10.1 \mathrm{~mL}$ vs. $34.3 \mathrm{~mL}$, $P=0.04)$, less hemorrhage (1.2 mL vs. $4.4 \mathrm{~mL}, P=0.01)$, and attenuated neurological deficits (NIHSS scores: 4 vs. $2, P=0.02$ ) on day 1. Furthermore, restrained lesion growth from day 1 to 7 ( $-2.3 \mathrm{~mL}$ vs. $12.1 \mathrm{~mL}, P<0.01)$, with better recovery on day 90 (mRS score $\leq 1: 73 \%$ vs. $32 \%, P<0.01$ ) was evident in patients given the combined medication. There were no SAEs.

More recently, Tian et al..$^{84}$ conducted a prospective, randomized, open-label, blinded endpoint trial, enrolling patients with occlusion of the internal carotid artery or proximal middle ce- 
rebral artery within 4.5 to 6 hours from symptom onset. Fortysix patients were randomly assigned to receive either IPA alone or tPA+fingolimod. Compared with the tPA monotherapy group, the fingolimod+tPA group exhibited greater early decrease in NIHSS score, as well as more favorable mRS distribution on day 90. They also exhibited a greater reduction in the non-perfusion lesion than those receiving tPA only, and this was accompanied by reduced infarct growth over 24 hours.

\section{Otaplimastat}

Otaplimastat, previously coded as SP-8203, is a small molecule with a quinazoline-2,4-dione scaffold. It has many potent neuroprotective effects mediated through anti-excitotoxic, anti-oxidant, and anti-inflammatory pathways. ${ }^{85-88}$ Preclinical evidence regarding otaplimastat has been evaluated in various animal models, including the rat focal and gerbil global ischemic models. ${ }^{85-88}$ When applied as a monotherapy, otaplimastat exhibits significant anti-ischemic and neuroprotective effects. Notably, in embolic stroke models, combined treatment with otaplimastat significantly reduced infarct volume, edema, ICH occurrence, and mortality after delayed tPA treatment ( 6 hours after ischemia onset)..$^{88}$ Otaplimastat stabilizes the BBB in subjects receiving tPA by both inhibiting tPA-induced MMP activity and inducing tissue inhibitors of metalloproteinases (TIMPs) (submitted). Otaplimastat also decreased the expression of EMMPRIN/CD147, an inducer of MMP synthesis, whose expression is specifically elevated in cerebral vascular endothelial cells after delayed tPA treatment.

In a phase I study, up to $240 \mathrm{mg}$ of otaplimastat was well tolerated, with no drug-related adverse events in 77 healthy volunteers (submitted). The Safety and Efficacy of Otaplimastat in Patients with AIS Receiving recombinant tPA (SAFE-TPA) study was a phase $2 a$ trial that assessed the safety and efficacy of otaplimastat in patients receiving IPA.

This was a two-stage, multicenter trial in AIS patients receiving tPA. Stage 1 constituted a single-arm, open-label safety study in 11 patients. Otaplimastat $(80 \mathrm{mg}$ ) was administered twice daily for 3 days. Stage 2 was a randomized, double-blind, placebo-controlled study involving 69 patients, assigned (1:1:1) to the otaplimastat $(40 \mathrm{mg})$, otaplimastat $(80 \mathrm{mg})$, or placebo group. IV otaplimastat or placebo was administered no later than 30 minutes after starting tPA infusion, and the study drugs were given twice daily six times, at intervals of 12 hours.

The primary endpoint was the occurrence of ICH on day 1. Secondary endpoints included SAEs, mortality, and mRS scores at 90 days (clinicaltrials.gov identifier: NCT02787278). No safety issues were encountered during stage 1 . The incidence of ICH during stage 2 was $0 / 22$ with the placebo, 0/22 with otaplimastat $(40 \mathrm{mg})$, and 1/21 with the $80 \mathrm{mg}$ dose, indicating no treatment difference. No significant differences in SAE $(13 \%, 17 \%, 14 \%)$ or deaths $(8.3 \%, 4.2 \%, 4.8 \%)$ were observed among the three groups. Three adverse events (chills, muscle rigidity, hepatotoxicity) were judged to be related to otaplimastat. The mRS distribution was more favorable for otaplimastat $40 \mathrm{mg}$ than for the placebo (submitted). Thus, IV otaplimastat adjunctive therapy in patients receiving tPA was feasible and generally safe, and the signal of improved functional outcome with otaplimastat $40 \mathrm{mg}$ justifies further large trials (in submission). Currently, a phase Illb study is ongoing to obtain more evidence of otaplimastat's clinical efficacy.

\section{Epigallocatechin gallate}

Epigallocatechin gallate (EGCG) is an extract of green tea that has antioxidant and neuroprotective effects. ${ }^{89}$ It improved limb paresis in a rat stroke model. ${ }^{90}$ In one study, rats subject to transient MCAO received either IV TPA or TPA+EGCG (20 $\mathrm{mg} / \mathrm{kg}$ ) at 4 hours. Compared with monotherapy, tPA+EGCG significantly reduced infarct volume, edema, and BBB breakage; it also up-regulated PAI-1 and down-regulated MMP-2 and MMP-9 expression in the brain. ${ }^{91}$

In another study, 371 patients with AIS were randomly assigned according to their onset-to-treatment time. They were then treated with IV tPA+EGCG (500 mg/day for 7 days) or IV tPA+placebo. Treatment outcome was assessed using NIHSS scores and plasma levels of MMP-2 and MMP-9. The tPA+EGCG treatment significantly improved NIHSS scores compared with the placebo in patients with delayed onset-totreatment time strata, whereas outcomes did not differ in patients treated $<3$ hours. This improved outcome may have been due to the reduction in plasma levels of MMP-2 and MMP-9, as both showed strong linear correlations with NIHSS score in all patients. ${ }^{92}$ These results suggest that EGCG could be used as an adjunctive drug during tPA treatment, especially when such treatment is delayed.

\section{Can these drugs be used in reperfusion therapy without using tPA?}

EVT is effective in patients with large artery occlusion., ${ }^{5,93,94}$ In those who visit $>4.5$ hours after symptom onset, EVT is performed without tPA therapy. The evidence regarding the drugs described above is typically based on favorable results in animal experiments, where the agents are applied in cases of delayed (4- or 6-hour) tPA therapy. Therefore, it remains unclear whether the drugs work in patients undergoing EVT 
without tPA therapy.

Theoretically, the increased risk of ICH and HT after EVT does not differ significantly from that after IV tPA treatment ${ }_{1}^{5}$ and failure to achieve good functional outcome occurs in up to $50 \%$ of patients, even those who have experienced successful EVT. ${ }^{95}$ This lack of efficacy may be associated with persistent ischemic injury due to delayed treatment, poor cerebral collaterals, re-occlusion, and microcirculation impairment. ${ }^{50,95-99}$ In addition, oxidative damage, inflammation, edema formation, and HT associated with BBB breakdown appear to play a role, as described above. Thus, the mechanism of brain damage appears to be similar between tPA and EVT therapies.

In one study, investigators attempted to differentiate the pathophysiology of brain damage between mechanical reperfusion and IV tPA using spontaneously hypertensive rats. ${ }^{100}$ Mechanical ischemia/reperfusion was achieved by using an intraluminal filament to occlude the MCA for 2 hours. Thrombolytic reperfusion was achieved by administering tPA 2 hours after embolic MCAO. Regional cortical blood flow was monitored using laser-Doppler flowmetry, and BBB permeability in the cortex was measured in terms of Evans blue dye leakage. Cortical MMP-9 levels were assessed using zymography and immunohistochemistry. Blood flow completely recovered during mechanical reperfusion in both the central and peripheral areas of the ischemic cortex whereas after IV tPA, reperfusion was incomplete, with moderate recovery in the periphery only. $\mathrm{BBB}$ permeability was mainly increased in the central regions of the ischemic cortex after mechanical reperfusion, but it was increased in both the central and peripheral areas after IV tPA. Overall, MMP-9 levels were higher after tPA therapy, even though ischemic injury was similar in both models after 24 hours. Thus, the profiles of blood flow recovery, BBB leakage, and MMP-9 up-regulation differ between mechanical and thrombolytic reperfusion after focal ischemia.

Thus, drugs that stabilize the BBB may be more useful in patients receiving IV tPA than in those treated with EVT. However, in our clinical practice, tPA treatment is performed earlier than $\mathrm{EVT}$, and we only use EVT in patients that show persistent vascular occlusion after tPA therapy. Thus, this animal result cannot be directly applied to our clinical practice. Taken together, it is not yet clear whether these drugs are less effective in patients receiving EVT than in those treated with IPA, so further clinical trials using these drugs are warranted in patients receiving EVT as well.

\section{Summary and future directions}

As described above, many drugs have shown benefits in animal models, usually rat MCAO, treated with PPA. However, only a small number of drugs have entered into clinical study stage. For safety reasons, agents that are already in use in clinical practice (e.g., statins, minocycline, tirofiban, argatroban) can enter clinical studies more easily. Other drugs require more time and funding to be tested for safety (phase 1 study).

Even when agents are proven to be safe, human trials are still limited by several factors. Firstly, it is difficult to obtain funds. Although drugs that have been in clinical use may have an advantage in terms of safety, pharmacological companies typically have insufficient enthusiasm for clinical studies aimed at different therapeutic targets and are unwilling to invest funds for old drugs.

Secondly, it would be difficult to recruit sufficient numbers of patients to carry out trials; tPA is administered to less than $10 \%$ of stroke patients. Moreover, because these agents are likely to work when administered quite early, the therapeutic time window for tPA helpers may be very narrow. One study showed that the median estimate of time from onset of ischemia to BBB disruption was 3.8 hours. ${ }^{101}$ Moreover, for severe stroke patients, it would be difficult to take the drugs orally. Future trials may have to consider administering the drugs during transportation (in the ambulance).

Thirdly, some drugs are difficult to use in a trial because of their original effects. For example, two statin trials described above suffered from early termination because of slow enrollment; investigators were uncomfortable withholding statins from AIS patients, given that much evidence indicates that statins prevent further stroke. Despite these difficulties, many ongoing trials are comparing the efficacy of tPA with that of tPA+helpers, and I hope that new therapeutic strategies will arise in the near future.

Finally, thrombolytic drugs with fewer side effects than IPA have been developed. One example is tenecteplase (TNK). It is not yet known whether this drug indeed has less marked tPA toxicity (personal communication with TNK investigators). Currently, ongoing trials are comparing the efficacy and hazards of tPA and TNK in patients with AIS, and TPA may be replaced by TNK in the future. It may then be necessary to carry out studies comparing TNK with tPA+tPA helpers. If TNK wins this race, would these tPA helpers become obsolete? I doubt it. As discussed above, although many of the drugs were tested in animal stroke models that use tPA, most are likely to be useful in ischemic/reperfusion damage unassociated with TPA as well. Thus, these drugs would also constitute TNK helpers, so future 
studies may need to compare TNK with TNK+TNK helpers.

\section{Disclosure}

The author has no financial conflicts of interest.

\section{Acknowledgments}

This study was supported by a grant from the Korea Health Technology R\&D project through the Korea Health Industry Development Institute (KHIDI), funded by the Ministry of Health and Welfare, Republic of Korea (HI15C2796).

\section{References}

1. National Institute of Neurological Disorders and Stroke rt-PA Stroke Study Group. Tissue plasminogen activator for acute ischemic stroke. N Engl J Med 1995;333:1581-1587.

2. Hacke $W$, Kaste $M$, Bluhmki E, Brozman M, Dávalos $A$, Guidetti $D$, et al. Thrombolysis with alteplase 3 to 4.5 hours after acute ischemic stroke. N Eng/ J Med 2008;359:1317-1329.

3. Emberson J, Lees KR, Lyden P, Blackwell L, Albers G, Bluhmki $E$, et al. Effect of treatment delay, age, and stroke severity on the effects of intravenous thrombolysis with alteplase for acute ischaemic stroke: a meta-analysis of individual patient data from randomised trials. Lancet 2014;384:1929-1935.

4. Lees KR, Emberson J, Blackwell L, Bluhmki E, Davis SM, Donnan $\mathrm{GA}$, et al. Effects of alteplase for acute stroke on the distribution of functional outcomes: a pooled analysis of 9 trials. Stroke 2016;47:2373-2379.

5. Goyal M, Menon BK, van Zwam WH, Dippel DW, Mitchell PJ, Demchuk AM, et al. Endovascular thrombectomy after largevessel ischaemic stroke: a meta-analysis of individual patient data from five randomised trials. Lancet 2016;387:1723-1731.

6. Saver JL, Fonarow GC, Smith EE, Reeves MJ, Grau-Sepulveda MV, Pan W, et al. Time to treatment with intravenous tissue plasminogen activator and outcome from acute ischemic stroke. JAMA 2013;309:2480-2488.

7. Jickling GC, Liu D, Stamova B, Ander BP, Zhan X, Lu A, et al. Hemorrhagic transformation after ischemic stroke in animals and humans. J Cereb Blood Flow Metab 2014;34:185-199.

8. Shi ZS, Duckwiler GR, Jahan R, Tateshima S, Szeder V, Saver $J \mathrm{~L}$, et al. Early blood-brain barrier disruption after mechanical thrombectomy in acute ischemic stroke. J Neuroimaging 2018;28:283-288.

9. Wang $X$, Tsuji $K$, Lee SR, Ning M, Furie KL, Buchan AM, et al. Mechanisms of hemorrhagic transformation after tissue plasminogen activator reperfusion therapy for ischemic stroke. Stroke 2004;35(11 Suppl 1):2726-2730.

10. Simard JM, Kent TA, Chen M, Tarasov KV, Gerzanich V. Brain oedema in focal ischaemia: molecular pathophysiology and theoretical implications. Lancet Neurol 2007;6:258-268.

11. Kastrup A, Gröschel $K$, Ringer TM, Redecker $C$, Cordesmeyer $\mathrm{R}$, Witte $\mathrm{OW}$, et al. Early disruption of the blood-brain barrier after thrombolytic therapy predicts hemorrhage in patients with acute stroke. Stroke 2008;39:2385-2387.

12. Wang $W, L i M, C h e n ~ Q$, Wang J. Hemorrhagic transformation after tissue plasminogen activator reperfusion therapy for ischemic stroke: mechanisms, models, and biomarkers. Mol Neurobiol 2015;52:1572-1579.

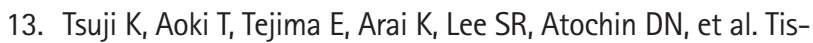
sue plasminogen activator promotes matrix metalloproteinase-9 upregulation after focal cerebral ischemia. Stroke 2005;36:1954-1959

14. Montaner J, Molina CA, Monasterio J, Abilleira S, Arenillas JF, Ribó $M$, et al. Matrix metalloproteinase-9 pretreatment level predicts intracranial hemorrhagic complications after thrombolysis in human stroke. Circulation 2003;107:598-603.

15. Dirnagl U, ladecola C, Moskowitz MA. Pathobiology of ischaemic stroke: an integrated view. Trends Neurosci 1999;22: 391-397.

16. Fisher M. New approaches to neuroprotective drug development. Stroke 2011;42(1 Suppl):S24-S27.

17. Savitz Sl, Baron JC, Yenari MA, Sanossian N, Fisher M. Reconsidering neuroprotection in the reperfusion era. Stroke 2017:48:3413-3419.

18. Fisher M, Feuerstein G, Howells DW, Hurn PD, Kent TA, Savitz $\mathrm{SI}$, et al. Update of the stroke therapy academic industry roundtable preclinical recommendations. Stroke 2009;40: 2244-2250.

19. Albers GW, Goldstein LB, Hess DC, Wechsler LR, Furie KL, Gorelick PB, et al. Stroke Treatment Academic Industry Roundtable (STAIR) recommendations for maximizing the use of intravenous thrombolytics and expanding treatment options with intra-arterial and neuroprotective therapies. Stroke 2011;42:2645-2650.

20. Switzer JA, Hess DC, Ergul A, Waller JL, Machado LS, Portik-

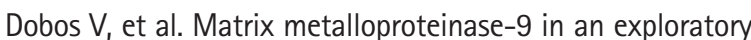
trial of intravenous minocycline for acute ischemic stroke. Stroke 2011;42:2633-2635.

21. Powers WJ, Rabinstein AA, Ackerson T, Adeoye OM, Bambakidis NC, Becker K, et al. 2018 Guidelines for the early management of patients with acute ischemic stroke: a guideline for healthcare professionals from the American Heart Association/American Stroke Association. Stroke 2018;49:e46-e110.

22. Amar AP, Sagare AP, Zhao Z, Wang Y, Nelson AR, Griffin JH, 
et al. Can adjunctive therapies augment the efficacy of endovascular thrombolysis? A potential role for activated protein C. Neuropharmacology 2018;134(Pt B):293-301.

23. Seitz RJ, Meisel S, Moll M, Wittsack HJ, Junghans U, Siebler $M$. The effect of combined thrombolysis with rtPA and tirofiban on ischemic brain lesions. Neurology 2004;62:21102112.

24. Barreto AD, Ford GA, Shen L, Pedroza C, Tyson J, Cai $C$, et al. Randomized, multicenter trial of ARTSS-2 (Argatroban With Recombinant Tissue Plasminogen Activator for Acute Stroke). Stroke 2017;48:1608-1616.

25. Lapchak PA. Tumor necrosis factor-alpha is involved in thrombolytic-induced hemorrhage following embolic strokes in rabbits. Brain Res 2007;1167:123-128.

26. Chen W, Hartman R, Ayer R, Marcantonio S, Kamper J, Tang $J$, et al. Matrix metalloproteinases inhibition provides neuroprotection against hypoxia-ischemia in the developing brain. J Neurochem 2009;111:726-736.

27. Mishiro $K_{1}$ Ishiguro $M$, Suzuki $Y$, Tsuruma $K$, Shimazawa $M_{1}$ Hara $\mathrm{H}$. A broad-spectrum matrix metalloproteinase inhibitor prevents hemorrhagic complications induced by tissue plasminogen activator in mice. Neuroscience 2012;205:39-48.

28. Shehadah A, Chen J, Cui Y, Zhang L, Roberts C, Lu M, et al. Combination treatment with low-dose Niaspan and tissue plasminogen activator provides neuroprotection after embolic stroke in rats. J Neurol Sci 2011;309:96-101.

29. Liu SF, Ye X, Malik AB. Inhibition of NF-kappaB activation by pyrrolidine dithiocarbamate prevents in vivo expression of proinflammatory genes. Circulation 1999;100:1330-1337.

30. Wang Z, Shan W, Cao J, Wintermark M, Huang W, Zuo Z. Early administration of pyrrolidine dithiocarbamate extends the therapeutic time window of tissue plasminogen activator in a male rat model of embolic stroke. J Neurosci Res 2018; 96:449-458.

31. Tan Z, Turner RC, Leon RL, Li X, Hongpaisan J, Zheng W, et al. Bryostatin improves survival and reduces ischemic brain injury in aged rats after acute ischemic stroke. Stroke 2013;44:34903497.

32. Tan Z, Lucke-Wold BP, Logsdon AF, Turner RC, Tan C, Li X, et al. Bryostatin extends tPA time window to $6 \mathrm{~h}$ following middle cerebral artery occlusion in aged female rats. Eur J Pharmacol 2015;764:404-412.

33. Li Q, Han X, Lan $X$, Hong $X$, Li Q, Gao Y, et al. Inhibition of tPA-induced hemorrhagic transformation involves adenosine $\mathrm{A} 2 \mathrm{~b}$ receptor activation after cerebral ischemia. Neurobiol Dis 2017;108:173-182.

34. Won $\mathrm{S}$, Lee JH, Wali B, Stein DG, Sayeed I. Progesterone attenuates hemorrhagic transformation after delayed tPA treatment in an experimental model of stroke in rats: involvement of the VEGF-MMP pathway. J Cereb Blood Flow Metab 2014;34:72-80.

35. Sowndhararajan K, Deepa P, Kim M, Park SJ, Kim S. Neuroprotective and cognitive enhancement potentials of baicalin: a review. Brain Sci 2018;8:E104.

36. Chen H, Guan B, Chen X, Chen X, Li C, Qiu J, et al. Baicalin attenuates blood-brain barrier disruption and hemorrhagic transformation and improves neurological outcome in ischemic stroke rats with delayed t-PA treatment: involvement of ONOO(-)-MMP-9 pathway. Trans/ Stroke Res 2018;9:515529.

37. dela Peña IC, Yoo A, Tajiri N, Acosta SA, Ji X, Kaneko Y, et al. Granulocyte colony-stimulating factor attenuates delayed tPA-induced hemorrhagic transformation in ischemic stroke rats by enhancing angiogenesis and vasculogenesis. J Cereb Blood Flow Metab 2015;35:338-346.

38. Dela Peña IC, Yang S, Shen G, Fang Liang H, Solak S, Borlongan CV. Extension of tissue plasminogen activator treatment window by granulocyte-colony stimulating factor in a thromboembolic rat model of stroke. Int J Mol Sci 2018;19:E1635.

39. Zhang Z, Zhang L, Yepes M, Jiang $Q_{1}$ Li Q, Arniego P, et al. Adjuvant treatment with neuroserpin increases the therapeutic window for tissue-type plasminogen activator administration in a rat model of embolic stroke. Circulation 2002;106:740745.

40. Cai Y, Liu X, Chen W, Wang Z, Xu G, Zeng Y, et al. TGF- $\beta 1$ prevents blood-brain barrier damage and hemorrhagic transformation after thrombolysis in rats. Exp Neurol 2015;266:120126.

41. Brundula V, Rewcastle NB, Metz LM, Bernard CC, Yong VW. Targeting leukocyte MMPs and transmigration: minocycline as a potential therapy for multiple sclerosis. Brain 2002;125(Pt 6):1297-1308.

42. Murata $Y$, Rosell A, Scannevin RH, Rhodes KJ, Wang $X$, Lo EH. Extension of the thrombolytic time window with minocycline in experimental stroke. Stroke 2008;39:3372-3377.

43. Fan $X$, Lo EH, Wang $X$. Effects of minocycline plus tissue plasminogen activator combination therapy after focal embolic stroke in type 1 diabetic rats. Stroke 2013;44:745-752.

44. Malhotra K, Chang JJ, Khunger A, Blacker D, Switzer JA, Goyal N, et al. Minocycline for acute stroke treatment: a systematic review and meta-analysis of randomized clinical trials. J Neurol 2018;265:1871-1879.

45. Lampl Y, Boaz M, Gilad R, Lorberboym M, Dabby R, Rapoport $A$, et al. Minocycline treatment in acute stroke: an open-label, evaluator-blinded study. Neurology 2007;69:1404-1410.

46. Padma Srivastava MV, Bhasin A, Bhatia R, Garg A, Gaikwad 
$\mathrm{S}$, Prasad $\mathrm{K}$, et al. Efficacy of minocycline in acute ischemic stroke: a single-blinded, placebo-controlled trial. Neurol India 2012;60:23-28.

47. Sheng Z, Liu Y, Li H, Zheng W, Xia B, Zhang X, et al. Efficacy of minocycline in acute ischemic stroke: a systematic review and meta-analysis of rodent and clinical studies. Front Neurol 2018;9:1103.

48. Blacker DJ, Prentice D, Alvaro A, Bates TR, Bynevelt M, Kelly $A$, et al. Reducing haemorrhagic transformation after thrombolysis for stroke: a strategy utilising minocycline. Stroke Res Treat 2013;2013:362961.

49. Peña ID, Borlongan C, Shen G, Davis W. Strategies to extend thrombolytic time window for ischemic stroke treatment: an unmet clinical need. J Stroke 2017;19:50-60.

50. Chamorro Á. Neuroprotectants in the era of reperfusion therapy. J Stroke 2018;20:197-207.

51. Romanos E, Planas AM, Amaro S, Chamorro A. Uric acid reduces brain damage and improves the benefits of rt-PA in a rat model of thromboembolic stroke. J Cereb Blood Flow Metab 2007;27:14-20.

52. Amaro $S$, Laredo $C$, Renú A, Llull L, Rudilosso $S$, Obach $V$, et al. Uric acid therapy prevents early ischemic stroke progression: a tertiary analysis of the URICO-ICTUS trial (efficacy study of combined treatment with uric acid and r-tPA in acute ischemic stroke). Stroke 2016;47:2874-2876.

53. Chamorro Á, Amaro S, Castellanos M, Gomis M, Urra X, Blasco J, et al. Uric acid therapy improves the outcomes of stroke patients treated with intravenous tissue plasminogen activator and mechanical thrombectomy. Int J Stroke 2017;12:377382.

54. Cimino M, Gelosa P, Gianella A, Nobili E, Tremoli E, Sironi L. Statins: multiple mechanisms of action in the ischemic brain. Neuroscientist 2007;13:208-213.

55. Lapchak PA, Han MK. The 3-hydroxy-3-methylglutaryl coenzyme $A$ reductase inhibitor simvastatin reduces thrombolytic-induced intracerebral hemorrhage in embolized rabbits. Brain Res 2009;1303:144-150.

56. Zhang L, Chopp M, Jia L, Cui Y, Lu M, Zhang ZG. Atorvastatin extends the therapeutic window for tPA to $6 \mathrm{~h}$ after the onset of embolic stroke in rats. J Cereb Blood Flow Metab 2009;29:1816-1824.

57. Montaner J, Bustamante A, García-Matas S, Martínez-Za-

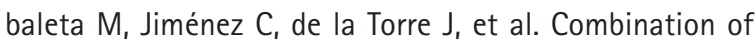
thrombolysis and statins in acute stroke is safe: results of the STARS randomized trial (stroke treatment with acute reperfusion and simvastatin). Stroke 2016;47:2870-2873.

58. Heo JH, Song D, Nam HS, Kim EY, Kim YD, Lee KY, et al. Effect and safety of rosuvastatin in acute ischemic stroke. $J$
Stroke 2016;18:87-95.

59. Yamashita T, Kamiya T, Deguchi K, Inaba T, Zhang H, Shang J, et al. Dissociation and protection of the neurovascular unit after thrombolysis and reperfusion in ischemic rat brain. $J$ Cereb Blood Flow Metab 2009;29:715-725.

60. Aoki J, Kimura K, Morita N, Harada M, Metoki N, Tateishi Y, et al. YAMATO study (tissue-type plasminogen activator and edaravone combination therapy). Stroke 2017;48:712-719.

61. Enomoto M, Endo A, Yatsushige $H$, Fushimi K, Otomo Y. Clinical effects of early edaravone use in acute ischemic stroke patients treated by endovascular reperfusion therapy. Stroke 2019;50:652-658.

62. Rha JH, Saver JL. The impact of recanalization on ischemic stroke outcome: a meta-analysis. Stroke 2007;38:967-973.

63. Rubiera M, Alvarez-Sabín J, Ribo M, Montaner J, Santamarina $E_{\text {, }}$ Arenillas JF, et al. Predictors of early arterial reocclusion after tissue plasminogen activator-induced recanalization in acute ischemic stroke. Stroke 2005;36:1452-1456.

64. Saqqur M, Molina CA, Salam A, Siddiqui M, Ribo M, Uchino $K$, et al. Clinical deterioration after intravenous recombinant tissue plasminogen activator treatment: a multicenter transcranial Doppler study. Stroke 2007;38:69-74.

65. Zinkstok SM, Roos YB; ARTIS investigators. Early administration of aspirin in patients treated with alteplase for acute ischaemic stroke: a randomized controlled trial. Lancet 2012; 380:731-737.

66. Zhang L, Zhang ZG, Zhang R, Morris D, Lu M, Coller BS, et al. Adjuvant treatment with a glycoprotein Ilb/Illa receptor inhibitor increases the therapeutic window for low-dose tissue plasminogen activator administration in a rat model of embolic stroke. Circulation 2003;107:2837-2843.

67. Straub $S$, Junghans U, Jovanovic V, Wittsack HJ, Seitz RJ, Siebler M. Systemic thrombolysis with recombinant tissue plasminogen activator and tirofiban in acute middle cerebral artery occlusion. Stroke 2004;35:705-709.

68. Li W, Lin L, Zhang M, Wu Y, Liu C, Li X, et al. Safety and preliminary efficacy of early tirofiban treatment after alteplase in acute ischemic stroke patients. Stroke 2016;47:26492651.

69. Jang IK, Gold HK, Leinbach RC, Fallon JT, Collen D. In vivo thrombin inhibition enhances and sustains arterial recanalization with recombinant tissue-type plasminogen activator. Circ Res 1990;67:1552-1561.

70. Morris DC, Zhang L, Zhang ZG, Lu M, Berens KL, Brown PM, et al. Extension of the therapeutic window for recombinant tissue plasminogen activator with argatroban in a rat model of embolic stroke. Stroke 2001;32:2635-2640.

71. Barreto AD, Alexandrov AV, Lyden P, Lee J, Martin-Schild S, 
Shen $L$, et al. The argatroban and tissue-type plasminogen activator stroke study: final results of a pilot safety study. Stroke 2012;43:770-775.

72. Berekashvili K, Soomro J, Shen L, Misra V, Chen PR, Blackburn $S$, et al. Safety and feasibility of argatroban, recombinant tissue plasminogen activator, and intra-arterial therapy in stroke (ARTSS-IA Study). J Stroke Cerebrovasc Dis 2018; 27:3647-3651.

73. Joyce DE, Gelbert L, Ciaccia A, DeHoff B, Grinnell BW. Gene expression profile of antithrombotic protein $c$ defines new mechanisms modulating inflammation and apoptosis. J Biol Chem 2001;276:11199-11203.

74. Griffin JH, Zlokovic BV, Mosnier LO. Activated protein C: biased for translation. Blood 2015;125:2898-2907.

75. Griffin JH, Zlokovic BV, Mosnier LO. Activated protein C, protease activated receptor 1 , and neuroprotection. Blood 2018;132:159-169.

76. Shibata $M$, Kumar SR, Amar A, Fernandez JA, Hofman F, Grif-

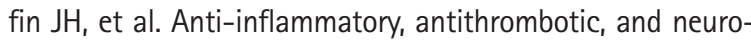
protective effects of activated protein $\mathrm{C}$ in a murine model of focal ischemic stroke. Circulation 2001;103:1799-1805.

77. Cheng T, Petraglia AL, Li Z, Thiyagarajan M, Zhong Z, Wu Z, et al. Activated protein $C$ inhibits tissue plasminogen activatorinduced brain hemorrhage. Nat Med 2006;12:1278-1285.

78. Wang Y, Zhang Z, Chow N, Davis TP, Griffin JH, Chopp M, et al. An activated protein $\mathrm{C}$ analog with reduced anticoagulant activity extends the therapeutic window of tissue plasminogen activator for ischemic stroke in rodents. Stroke 2012;43: 2444-2449.

79. Lyden P, Levy H, Weymer S, Pryor K, Kramer W, Griffin JH, et al. Phase 1 safety, tolerability and pharmacokinetics of 3K3A-APC in healthy adult volunteers. Curr Pharm Des 2013; 19:7479-7485.

80. Lyden P, Pryor KE, Coffey CS, Cudkowicz M, Conwit R, Jadhav $A$, et al. Final results of the RHAPSODY trial: a multi-center, phase 2 trial using a continual reassessment method to determine the safety and tolerability of 3K3A-APC, a recombinant variant of human activated protein $c_{1}$ in combination with tissue plasminogen activator, mechanical thrombectomy or both in moderate to severe acute ischemic stroke. Ann Neurol 2019;85:125-136.

81. Fu Y, Hao J, Zhang N, Ren L, Sun N, Li YJ, et al. Fingolimod for the treatment of intracerebral hemorrhage: a 2-arm proof-of-concept study. JAMA Neurol 2014;71:1092-1101.

82. Kraft $P$, Göb E, Schuhmann MK, Göbel K, Deppermann C, Thielmann I, et al. FTY720 ameliorates acute ischemic stroke in mice by reducing thrombo-inflammation but not by direct neuroprotection. Stroke 2013;44:3202-3210.
83. Zhu Z, Fu Y, Tian D, Sun N, Han W, Chang G, et al. Combination of the immune modulator fingolimod with alteplase in acute ischemic stroke: a pilot trial. Circulation 2015;132:11041112.

84. Tian DC, Shi K, Zhu Z, Yao J, Yang X, Su L, et al. Fingolimod enhances the efficacy of delayed alteplase administration in acute ischemic stroke by promoting anterograde reperfusion and retrograde collateral flow. Ann Neurol 2018;84:717-728.

85. Noh SJ, Lee JM, Lee KS, Hong HS, Lee CK, Cho IH, et al. SP8203 shows neuroprotective effects and improves cognitive impairment in ischemic brain injury through NMDA receptor. Pharmacol Biochem Behav 2011;100:73-80.

86. Noh SJ, Lee SH, Shin KY, Lee CK, Cho IH, Kim HS, et al. SP8203 reduces oxidative stress via SOD activity and behavioral deficit in cerebral ischemia. Pharmacol Biochem Behav 2011; 98:150-154.

87. Kim WK, Ju C, Jalin AMAA, Ryu JM, Cho IH, Kim WS, et al. Therapeutic efficacy and pharmacological mechanisms of sp8203 for treatment of cerebral ischemia. Stroke 2015;46(Suppl 1):ATP239.

88. Ju C, Anthony Jalin A, Song HY, Kim WK, Ryu JM, Cho GS, et al. Extension of therapeutic time window of tissue plasminogen activator with sp-8203 combination therapy in rat embolic stroke models. European Stroke Journal 2016;1(1 Suppl):581.

89. Han J, Wang M, Jing $X$, Shi H, Ren M, Lou H. (-)-Epigallocatechin gallate protects against cerebral ischemia-induced oxidative stress via Nrf2/ARE signaling. Neurochem Res 2014; 39:1292-1299.

90. Lim SH, Kim HS, Kim YK, Kim TM, Im S, Chung ME, et al. The functional effect of epigallocatechin gallate on ischemic stroke in rats. Acta Neurobiol Exp (Wars) 2010;70:40-46.

91. You YP. Epigallocatechin gallate extends the therapeutic window of recombinant tissue plasminogen activator treatment in ischemic rats. J Stroke Cerebrovasc Dis 2016;25:990997.

92. Wang XH, You YP. Epigallocatechin gallate extends therapeutic window of recombinant tissue plasminogen activator treatment for brain ischemic stroke: a randomized doubleblind and placebo-controlled trial. Clin Neuropharmacol 2017;40:24-28.

93. Albers GW, Marks MP, Kemp S, Christensen S, Tsai JP, OrtegaGutierrez S, et al. Thrombectomy for stroke at 6 to 16 hours with selection by perfusion imaging. N Engl J Med 2018;378: 708-718.

94. Nogueira RG, Jadhav AP, Haussen DC, Bonafe A, Budzik RF, Bhuva $P$, et al. Thrombectomy 6 to 24 hours after stroke with a mismatch between deficit and infarct. N Engl J Med 
2018;378:11-21.

95. Shi ZS, Liebeskind DS, Xiang B, Ge SG, Feng L, Albers GW, et al. Predictors of functional dependence despite successful revascularization in large-vessel occlusion strokes. Stroke 2014;45:1977-1984.

96. Kawiorski MM, Martínez-Sánchez P, Garcia-Pastor A, Calleja $P$, Fuentes B, Sanz-Cuesta BE, et al. Alberta Stroke Program Early CT Score applied to CT angiography source images is a strong predictor of futile recanalization in acute ischemic stroke. Neuroradiology 2016;58:487-493.

97. Gilberti N, Gamba M, Premi E, Costa A, Vergani V, Delrio I, et al. Leukoaraiosis is a predictor of futile recanalization in acute ischemic stroke. J Neurol 2017;264:448-452.

98. Hussein HM, Georgiadis AL, Vazquez G, Miley JT, Memon MZ, Mohammad YM, et al. Occurrence and predictors of futile recanalization following endovascular treatment among patients with acute ischemic stroke: a multicenter study. AJNR Am J Neuroradiol 2010;31:454-458.

99. Kim BM. Causes and solutions of endovascular treatment failure. J Stroke 2017;19:131-142.

100. Aoki T, Sumii T, Mori T, Wang X, Lo EH. Blood-brain barrier disruption and matrix metalloproteinase- 9 expression during reperfusion injury: mechanical versus embolic focal ischemia in spontaneously hypertensive rats. Stroke 2002;33:27112717.

101. Warach S, Latour LL. Evidence of reperfusion injury, exacerbated by thrombolytic therapy, in human focal brain ischemia using a novel imaging marker of early blood-brain barrier disruption. Stroke 2004;35(11 Suppl 1):2659-2661. 